\title{
Monitoring of Sudden Ionospheric Disturbance (SID) with 0-50 kHz Frequency Receiver over Aliero, Nigeria
}

\author{
Joshua Benjamin Wisdom ${ }^{1,}$, , Suleiman Muhammed Yushau ${ }^{1}$, Gwani Muhammad ${ }^{1}$, \\ Umar Muhammad Kangiwa ${ }^{1}$, Abbas Mustapha ${ }^{1}$, Oladipo Mumin Olatunji ${ }^{2}$ \\ ${ }^{1}$ Department of Physics, Kebbi State University of Science and Technology, Aliero, Nigeria \\ ${ }^{2}$ Department of Physics and Electronics, Koladaisi University, Ibadan, Nigeria
}

Email address:

benjaminjoshua7@gmail.com (J. B. Wisdom)

${ }^{*}$ Corresponding author

\section{To cite this article:}

Joshua Benjamin Wisdom, Suleiman Muhammed Yushau, Gwani Muhammad, Umar Muhammad Kangiwa, Abbas Mustapha, Oladipo Mumin Olatunji. Monitoring of Sudden Ionospheric Disturbance (SID) with 0-50 kHz Frequency Receiver over Aliero, Nigeria. International Journal of Astrophysics and Space Science. Vol. 9, No. 3, 2021, pp. 37-44. doi: 10.11648/j.ijass.20210903.11

Received: September 3, 2021; Accepted: September 18, 2021; Published: October 12, 2021

\begin{abstract}
Solar flares are known to produce fast Corona Mass Ejections (CMEs) that can lead to the occurrence of different classes of geomagnetic storms. Severe geomagnetic storms can generate disturbances in the magnetosphere and the ionosphere that can affect communication channels; by disrupting Satellite and navigation systems, such as GPS, Galileo, Compass and GLONASS. During intense Solar flares, enhancement in the ionospheric electron density usually occurs, leading to the absorption of the High Frequency (HF) signals by the ionosphere. Enhancement in the Very Low Frequency (VLF) radio waves (3-30 kHz) usually takes place during solar flares. This phenomenon is called Sudden Ionospheric Disturbance (SID). These SIDs serves as an opportunity for the tracking of solar flares using VLF. In this study, the diurnal variation of the VLF signals transmitted from six locations selected from USA, Australia and Japan were used to monitor SIDs. The signals were received using the 0-50 $\mathrm{kHz}$ frequency receiver (Super SID Monitor) installed at the Kebbi State University of Science and Technology (KSUST), Aliero, Nigeria (latitude: $12.31^{\circ} \mathrm{N}$ and Longitude: $4.50^{\circ} \mathrm{E}$ ). The diurnal variation of the VLF signals alongside some magnetic indices (Dst, $\mathrm{kp}$, and ap), solar wind speed and density as well as the solar flux index (f10.7) for the month of February, 2020 was investigated. Results from this study reveal that; the VLF amplitudes appeared to be stronger when the lowest level of the geomagnetic activity was recorded across all stations on the quietest day of the month. During this day, the intensity of the signals received vary across the stations, ranging from $2 * 10^{4}$ to $4 * 10^{7} \mathrm{~dB}$. During the disturbed period, decrease in the Disturbance Storm Time (Dst) index was observed to have two minimum excursion with values of -31 and $-33 \mathrm{nT}$, thus indicating a weak geomagnetic storm $(-30<\mathrm{Dst}>-50)$ event. Consequently a gradual increase in the solar wind speed with a peak value of $520 \mathrm{~km} / \mathrm{s}$, significant decrease in the VLF amplitude ranging from $50-7 * 10^{5} \mathrm{~dB}$ was observed during the weak geomagnetic storm, on 19 February, 2020. It is also evident from this study that the intensity/strength of the VLF signal and its pattern of propagation are greatly affected by the geomagnetic storm. In spite of the changes in the VLF amplitude observed, there was no trace of solar flares during the weak geomagnetic storm. This therefore suggests that not all classes of geomagnetic storms are connected to solar flares.
\end{abstract}

Keywords: Solar Flares, Ionosphere, Sudden Ionospheric Disturbance, Geomagnetic Storms, Space Weather

\section{Introduction}

The ionosphere is the major region of the atmosphere that is primarily responsible for radio wave propagation. Solar flares induce geomagnetic storms which in turn creates a disturbance in the magnetosphere and the Ionosphere that can affect communication channels. A solar flare is an abrupt and explosive discharge of energy (up to $10^{32} \mathrm{~J}$ ) from the active region of the Sun due to accumulated magnetic stress [1]. Solar flares travel with the speed of light and they can reach the earth within 480 seconds upon eruption from the sun, emitting radiation from radio waves (long wavelength) to gamma rays (short wave) that is across all electromagnetic spectrum [2]. The sun has a buoyant and active magnetic property that changes polarity every 11 years [3]. 
Although the heat energy released during a solar flare event has a minimal effect on the earth due to the earth atmosphere and the distance between the earth and the sun, the energetic particles and electromagnetic energy released possesses a great deal of danger. The effects of these energies on human activities include amongst many; the disruption of the ionospheric dynamics leading to the attenuation of the HighFrequency signals or radio blackout, disruption of Satellite and navigation systems [4] such as GPS, Galileo, Compass and GLONASS, Coronal Mass Ejections (CMEs) associated with solar flare can induce abrupt electric current on earth that could damage power systems like transformers. During intense Solar flare, enhancement in the ionospheric electron density usually occurs, thus, leading to the absorption of the HF by the ionosphere. On the other hand, very low frequency (VLF) radio waves $(3-30 \mathrm{kHz})$ are enhanced during solar flare events. This phenomenon is called Sudden Ionospheric Disturbance (SID). These SIDs serves as an opportunity for the tracking of solar flares using VLF. The VLF signals were also reported to be very useful in the study of extraterrestrial, atmospheric, geophysical and even earthquake events [5].

It is also known that Solar flares induce geomagnetic storm [6]; a temporary disturbance of the magnetosphere of the earth which is being triggered by a disorder in space weather linked with solar flares [7]. It affects the distribution of the ionospheric electron density, which in turn affects communication. It constitutes a great challenge in the transmission of high frequency (HF) radio signals. Some severe geomagnetic storms can even lead to radio blackouts, hence make living on earth very difficult. Geomagnetic storms are also known to cause changes in the ionosphere that can degrade the performance of global navigation satellite systems such as GPS, Galileo, Compass and GLONASS. They can induce currents in metallic pipelines; enhance galvanic corrosion in electric power transmission lines leading to voltage surges and shutdown. The losses that will be incurred as a result of severe geomagnetic storms if not checked could amount to billions of naira. This indeed calls for the need for effective and accurate prediction of geomagnetic storms, The strength of our prediction models lies in how much we understand the phenomenon, thus, calling for more studies particularly within the African sector.

The present study is aimed at; monitoring Sudden Ionospheric Disturbance (SID) using Very Low Frequency (VLF) signals received from six VLF transmitting stations, verifying the quiet and disturbed day morphology of SESSID data received at KSUST Aliero, track solar flares using Super SID receiver and also investigate the relationship between solar flares and pre-magnetic/weak geomagnetic storm signatures. Studies of this nature are of immense importance to the understanding of space weather. This is the very first time VLF signals are been received and studied during both quiet and disturbed conditions from this location.

\section{Data and Method}

In the analysis, the diurnal variation of some geomagnetic storm indices such as Dst, $\mathrm{kp}$, and ap was investigated alongside the solar wind speed and density as well as the solar flux index (f10.7), during geomagnetically quiet and disturbed periods. The quietest days for the month of study were first of all identified using the GFZ Postdam quiet day selection criteria available at http://www.gfzpotsdam.de/en/section/earths-magnetic-field/data-productsservices/kp-index/explanation/qd-days/. These most quiet days represent when the geomagnetic activities are minima in each month. The selection criteria, however, only give a qualified indication of the ionospheric activity in those days with respect to the other days of the same month. In the present study, geomagnetically disturbed days were considered as days for which Dst $\leq-30 n T, K p \geq$ 3 andAp $>15$. The data for the magnetic indices, solar flux index and the solar wind parameters were obtained from NSSDC's OMNI database (https://omniweb.gsfc.nasa.gov/form/dx1.html). On the other hand, the data for the various SID monitors installed around the world was archived in a centralized database hosted at Stanford Solar Centre and can be freely accessed through their website; http://sid.stanford.edu/database-browser/.

The signal strength from the various VLF stations received at Aliero (Table 1) during the most quiet days was compared with that of the disturbed period and thereafter the possible occurrence, time of occurrence and the intensity/classification of solar flares were investigated. This was achieved by comparing the data obtained at Aliero with the results of the occurrence of solar flares obtained from the Laboratory of X-ray Astronomy of the Sun, LPIRAS, Russia database which is accessible at http://tesis.lebedev.ru/en/sun_flares.html. The experimental set-up for the SID Monitor installed at the Kebbi State University of Science and Technology is shown in Figure 1. The loop antenna was locally constructed using a wooden frame of an area of $1 \mathrm{~m}^{2}$, it has 39 windings with 24 AWG wire with a diameter of $0.511 \mathrm{~mm}$.

Table 1. List of VLF transmitting stations.

\begin{tabular}{llllll}
\hline S/No & Station & Code & Frequency & Latitude & Longitude \\
\hline 1 & Cutler, ME, USA & NAA & 24 & $44.65^{\circ} \mathrm{N}$ & $67.3^{\circ} \mathrm{W}$ \\
2 & Jim Creek, WA, USA & NLK & 24.8 & $48.20^{\circ} \mathrm{N}$ & $121.92^{\circ} \mathrm{W}$ \\
3 & Lualualei, HI, USA & NPM & 21.4 & $20.4^{\circ} \mathrm{N}$ & $158.2^{\circ} \mathrm{W}$ \\
4 & LaMoure, ND, USA & NML & 25.2 & $46.35^{\circ} \mathrm{N}$ & $98.33^{\circ} \mathrm{W}$ \\
5 & Harold E. Holt & & & \\
& (North West Cape), & & & \\
& Australia & NWC & 19.8 & $21.8^{\circ} \mathrm{S}$ & $114.2^{\circ} \mathrm{E}$ \\
6 & Ebino, Japan & JJI & 22.2 & $32.04^{\circ} \mathrm{N}$ & $10.52^{\circ} \mathrm{E}$ \\
\hline
\end{tabular}




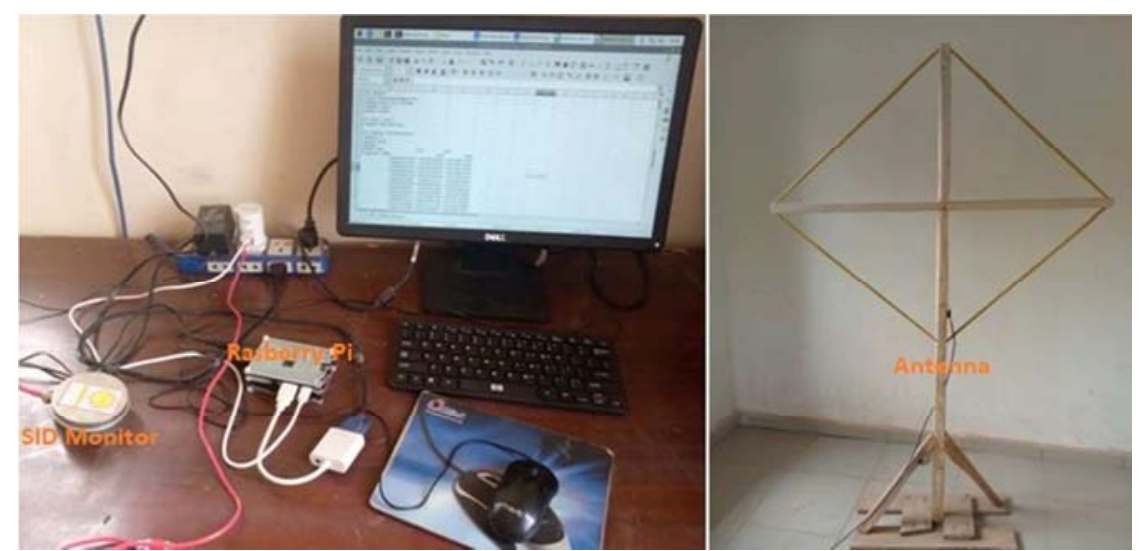

Figure 1. Experimental Set Up for the SID Monitor installed at the Kebbi State University of Science and Technology, Aliero, Nigeria.

A comprehensive list of the VLF stations can be obtained from; http://sidstation.lionelloudet.homedns.org/stations-listen.xhtml.

\section{Results and Discussion}

Figure 2 show the diurnal variation of (a) the planetary index (ap) and the interplanetary magnetic field, Bz (nT), (b) Solar Wind Speed $(\mathrm{km} / \mathrm{s})$ and Solar Wind Density $\left(\mathrm{Nkm}^{3}\right),(\mathrm{c})$ $\mathrm{kp}$ index and the Disturbance storm time (Dst) index in nT, (d) Solar flux (f10.7), during $25^{\text {th }}$ February 2020 (one of the most quiet days of the month). Observation from the Figure shows a slight rise in the geomagnetic activity around 00-0200 UT. This is evident from the southward orientation of the IMF Bz to a minimum value of about $-2 \mathrm{nT}$, with the planetary indices (ap and $\mathrm{kp}$ ) reaching a peak value of 5 and 13 respectively. Increase in the solar wind speed $(>400 \mathrm{~km} / \mathrm{s})$ was also observed at 0100 UT. The minimum value of the Dst for the 24 hours was $-12 \mathrm{nT}$, thus indicating a minimal level of geomagnetic activity, thus without any trace of a geomagnetic storm event on that day. The solar activity seems to be relatively low, with asolar flux index value that is less than $70(\mathrm{f} 10.7<70)$. It is also evident from Figure $2 \mathrm{~b}$ that the peak value of the solar wind speed corresponds well with the minimum value of the solar wind density and vice versa. These observations are a clear indication that $25^{\text {th }}$ February 2020 was a typical geomagnetically quiet day.

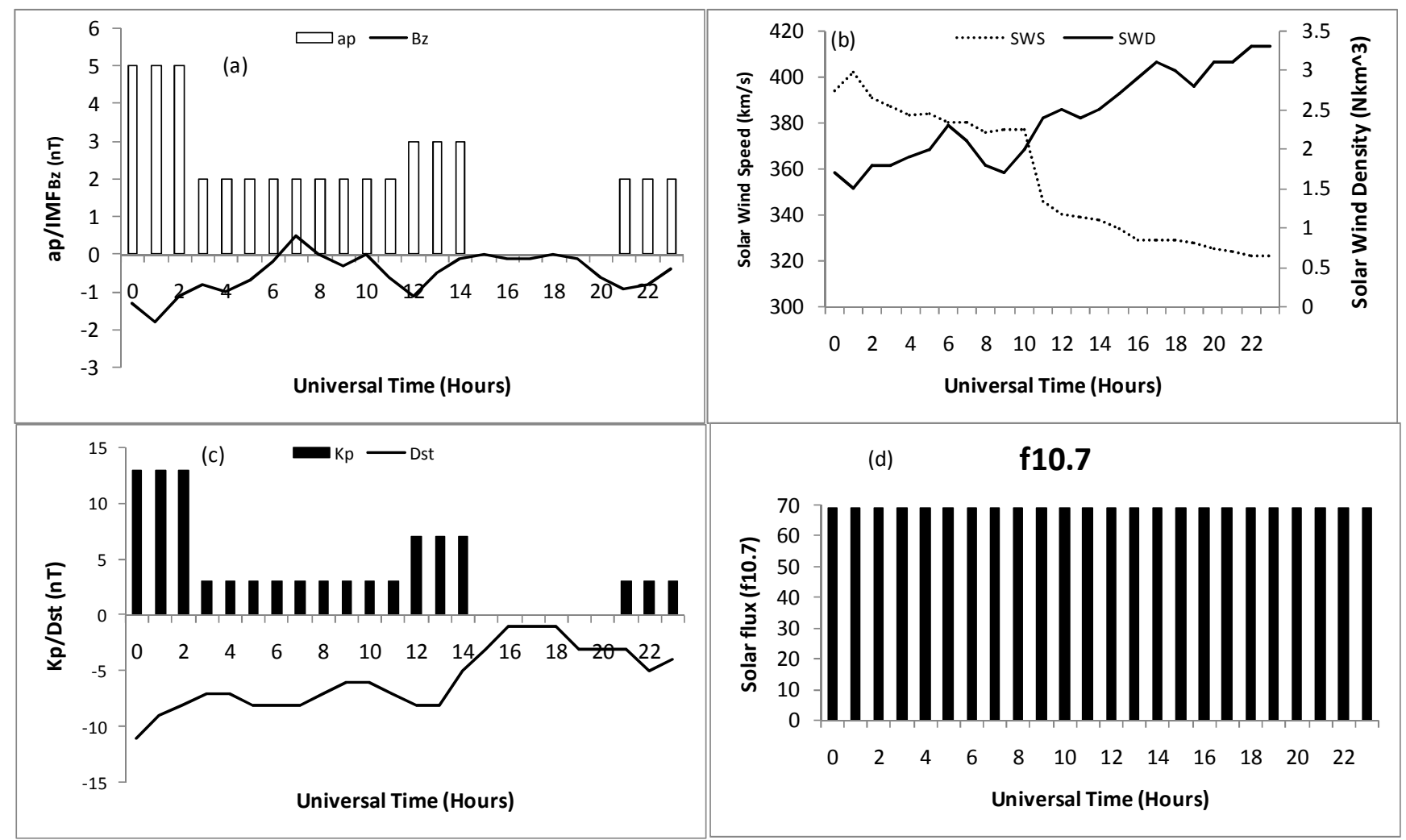

Figure 2. Diurnal variation of some Geomagnetic indices for on a typical geomagnetically quiet day $25^{\text {th }}$ February 2020. 
Figure 3, depicts the diurnal variation of the VLF signals from (top to bottom) JJI, NAA, NLK, MNL, NPN and NWC, received by the SID monitor installed at the Kebbi State University of Science and Technology, Aliero (KSUSTA), Nigeria. The signals appeared to be stronger when the lowest level of the geomagnetic activity for the 24 hours was observed, particularly within the time interval of $1500-1700$ UT across all stations. This suggests that an increase in the geomagnetic activity is likely to suppress the strength/intensity of the VLF signals transmitted and received by the SID monitors. The intensity of the signals received at this station is observed to vary across the stations, ranging from $2 * 10^{4}$ to $4 * 10^{7} \mathrm{~dB}$ with the peak value recorded at NWC and lowest at NLK. It is also observed from the Figure that the duration of the rise and decay of this high signals is same across the stations, although the time of occurrence of the peak values from each station vary, but the signal pattern is quite similar. This cannot be unconnected to their geographic location, transmitting frequency of the stations and the local time effect.

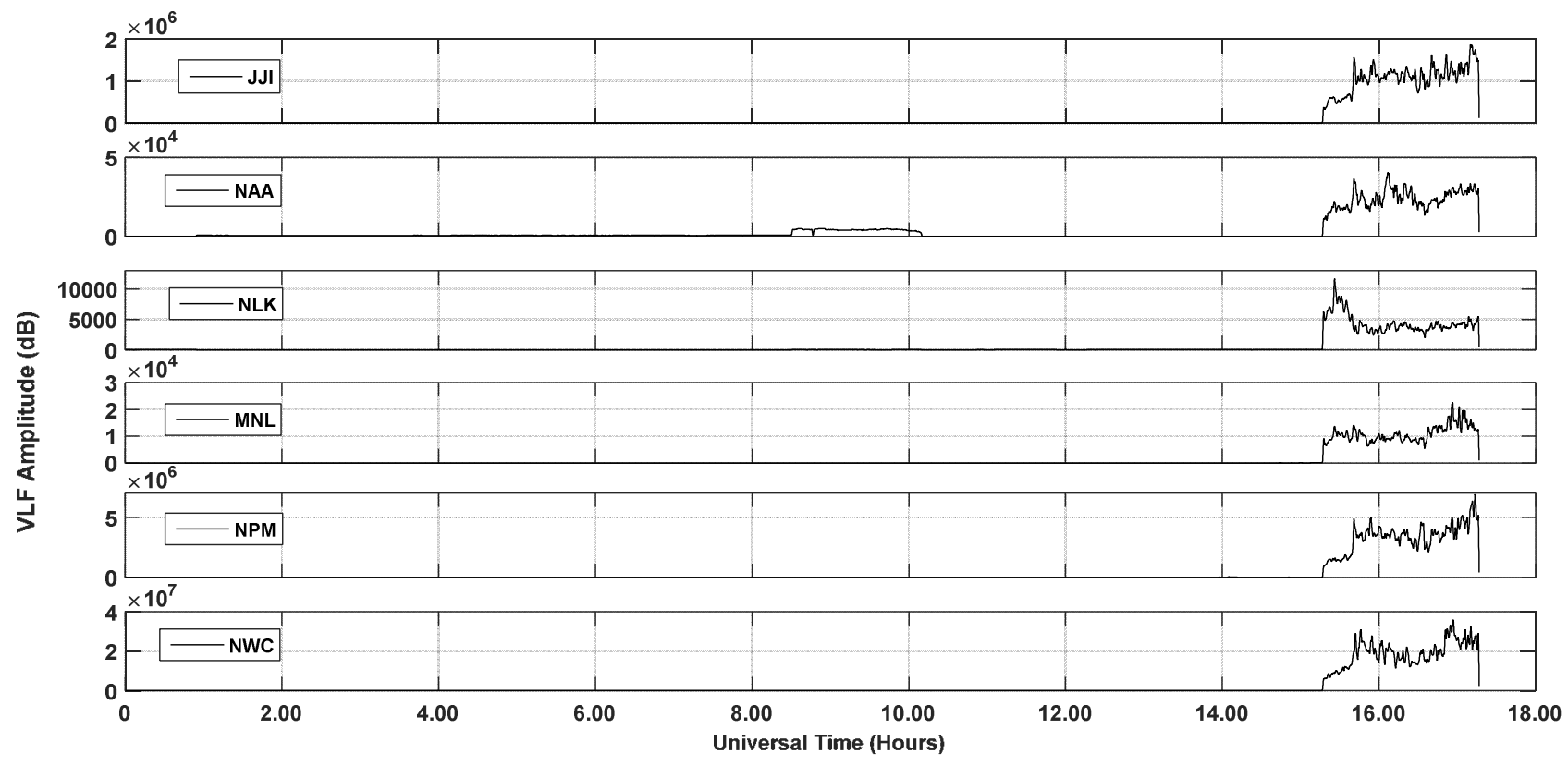

Figure 3. Diurnal variation of VLF signal from various stations received at Aliero on a typical geomagnetically quiet day $25^{\text {th }}$ February, 2020.

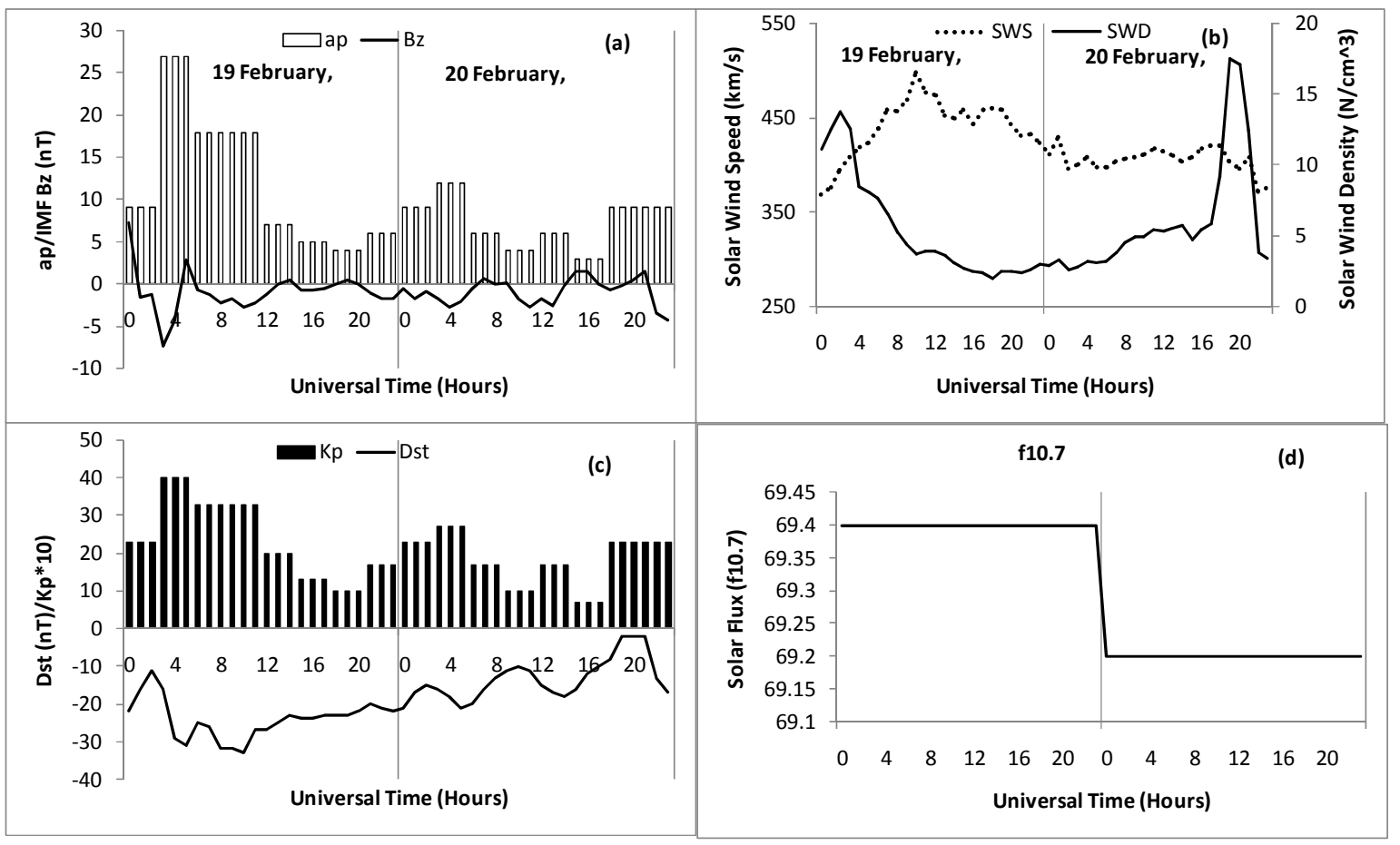

Figure 4. Diurnal variation of some Geomagnetic indices for 19-20 $0^{\text {th }}$ February, 2020. 
Figure 4, depicts the plot for (a) IMF Bz/ap index, (b) Solar Wind Speed and Solar Wind Density, (c) Dst index in nT/kp*10 index, and (d) Solar flux (f10.7) index. A closer look at the Figure reveals a relatively higher geomagnetic activity on day 19 compared to 20 February, 2020. It can be seen that the IMF Bz enjoyed a southward orientation during the early hours of $19^{\text {th }}$ February, 2020 with a threshold value of $-7 \mathrm{nT}$ at $0300 \mathrm{UT}$ (Figure $4 \mathrm{a}$ ), which is sufficient to drive a geomagnetic storm [8], this also coincides well with the peak values of $\mathrm{kp}$ and ap indices. $[9,10]$ has shown that the IMF $\mathrm{Bz}$ is the parameter that determines the occurrence of a geomagnetic storm, as the input of energy into the magnetosphere is directly dependent on the orientation (North-south) of the IMF Bz [11]. When the IMF Bz turns southward, it is indicative of the opening of the magnetosphere [12] that can lead to the input of energy into the magnetosphere. [8] Has earlier shown a strong dependence of geomagnetic storms to strong down to dusk electric fields accredited to the long duration of the southward orientation of the IMF Bz.

A decrease in the Dst index was also observed, commencing around $0200 \mathrm{UT}$ and had two minimum excursion with values of -31 and $-33 \mathrm{nT}$ at $0500 \mathrm{UT}$ and 1000 UT respectively (Figure 4c). This is indicative of a weak geomagnetic storm $(-30<$ Dst $>-50)$ as shown by $[13,14$ and 7]. Consequently a gradual increase in the solar wind speed was observed from 00 UT to a peak value of $520 \mathrm{~km} / \mathrm{s}$ at 1100 UT (Figure 4c) on 19 February, 2020. Although the peak values of the solar wind density correspond well with the IMF $\mathrm{Bz}$ on 19 February, it is evident that the solar wind speed and the solar wind density shares an inverse relationship. A slight drop in the solar flux (f10.7) index from 69.4 on 19 February to 69.2 on 20 February was observed.

On the other hand, Figures 5 and 6 shows the plot of the VLF signals received from (from top to bottom) JJ1, NAA, NLK, MNL, NPN and NWC, received by the SID monitor installed at KSUSTA on 19 and 20 February respectively. Observations from Figure 5 shows that the signal strength increased significantly between 1000 UT to 1300 UT and for all stations. It can also be seen that although several peaks were observed across all stations (except for NAA), it is evident that the peak values of the signal strength were recorded around noon. This period falls within the main phase of the geomagnetic storm and the early part of its recovery phase. A significant decrease in the intensity of the signal was observed on this day with the values ranging from $50-7 * 10^{5} \mathrm{~dB}$ compared to that recorded during the geomagnetically quiet day (Figure 3 ). The highest intensity of the signal received was transmitted from NWC, followed by NPM and lowest from NLK. It is also evident from this study that the intensity/strength of the signal and its pattern of propagation are greatly affected by the geomagnetic storm.

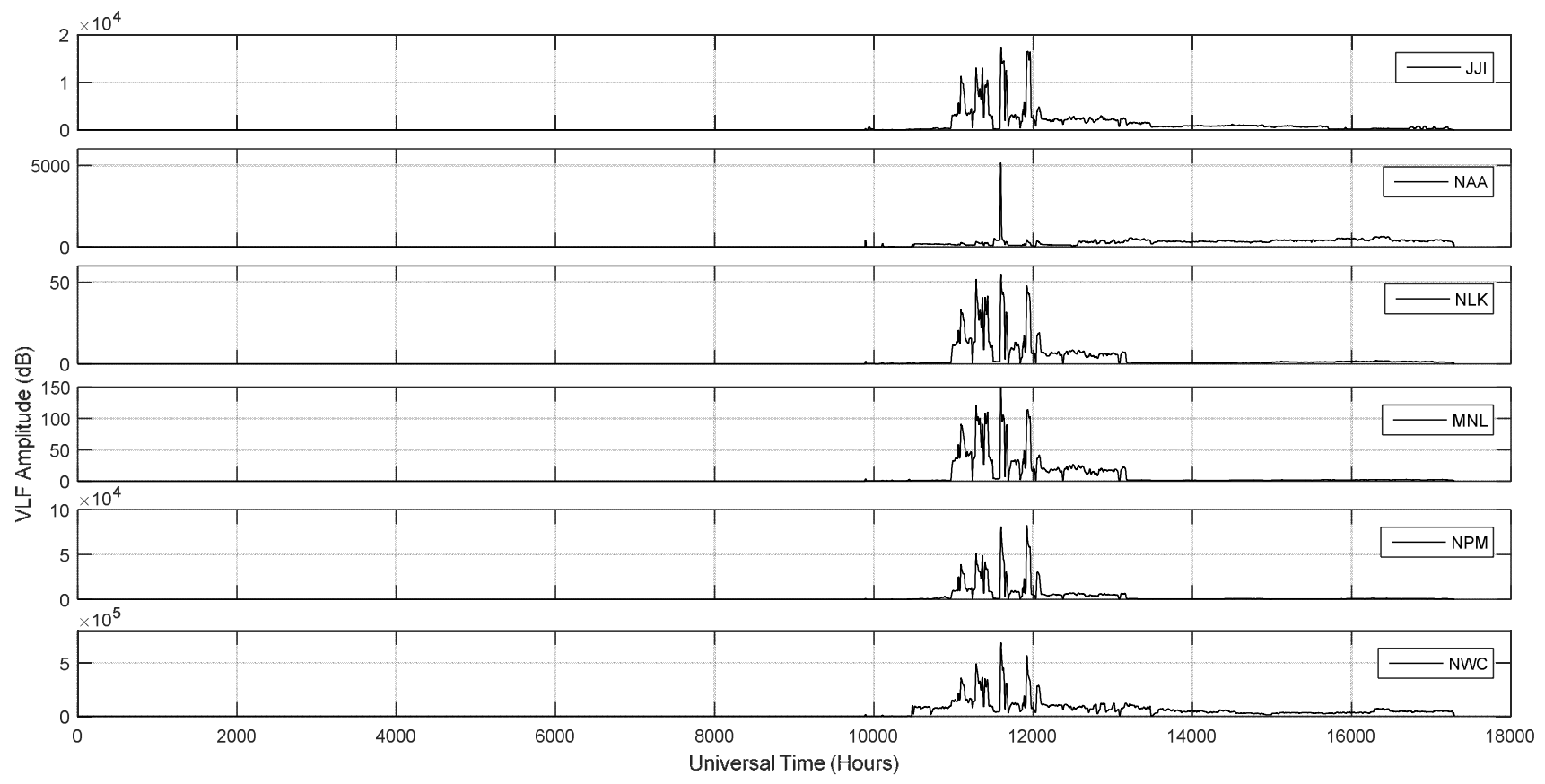

Figure 5. Diurnal variation of VLF signal (VLF amplitude in decibels) from various stations received at Aliero on $19^{\text {th }}$ February, 2020.

20 February, 2020 was characterised by several NorthSouth orientation of the IMF Bz, rise and fall in the ap, kp and the Dst indices as well as a decrease in the solar wind speed and Solar flux index (Figure 4a-d). This observation is not unconnected with the several peaks occurring at different time intervals and a complete change in the signal pattern of propagation on this day. On the average, the highest signal strength was received from NWC $\left(3 * 10^{5} \mathrm{~dB}\right)$, followed by NPM $\left(5^{*} 10^{4} \mathrm{~dB}\right)$ and the least was from NLK $(20 \mathrm{~dB})$. In comparison with the observations of Figure 5, a further decline in the intensity of the signals and a scattered signal pattern with relatively higher signal values occurring during 
20 February, 2020. It is also evident that most of these signal fluctuations, occurred during a change in the orientation of the IMF $\mathrm{Bz}$ from south to north or vice vassal and also an increase in the Dst index.

Adeniyi J. O [15] cited by [5] have observed that variations (short or long time) in the electron density of the D layer, appears as a fluctuation in the amplitude and phase of the VLF signals as well as the low frequency signals $(30-300 \mathrm{kHz})$. It is also known that geomagnetic storm affects greatly the distribution of the ionospheric electron density [16, 17], leading to the absorption and attenuation of Radio waves. Therefore it can be argued that this variation in the pattern of propagation and the accompanied decreases in the received VLF signals in this location cannot be unconnected with the effect of the geomagnetic storms on the $\mathrm{D}$ region of the ionosphere.

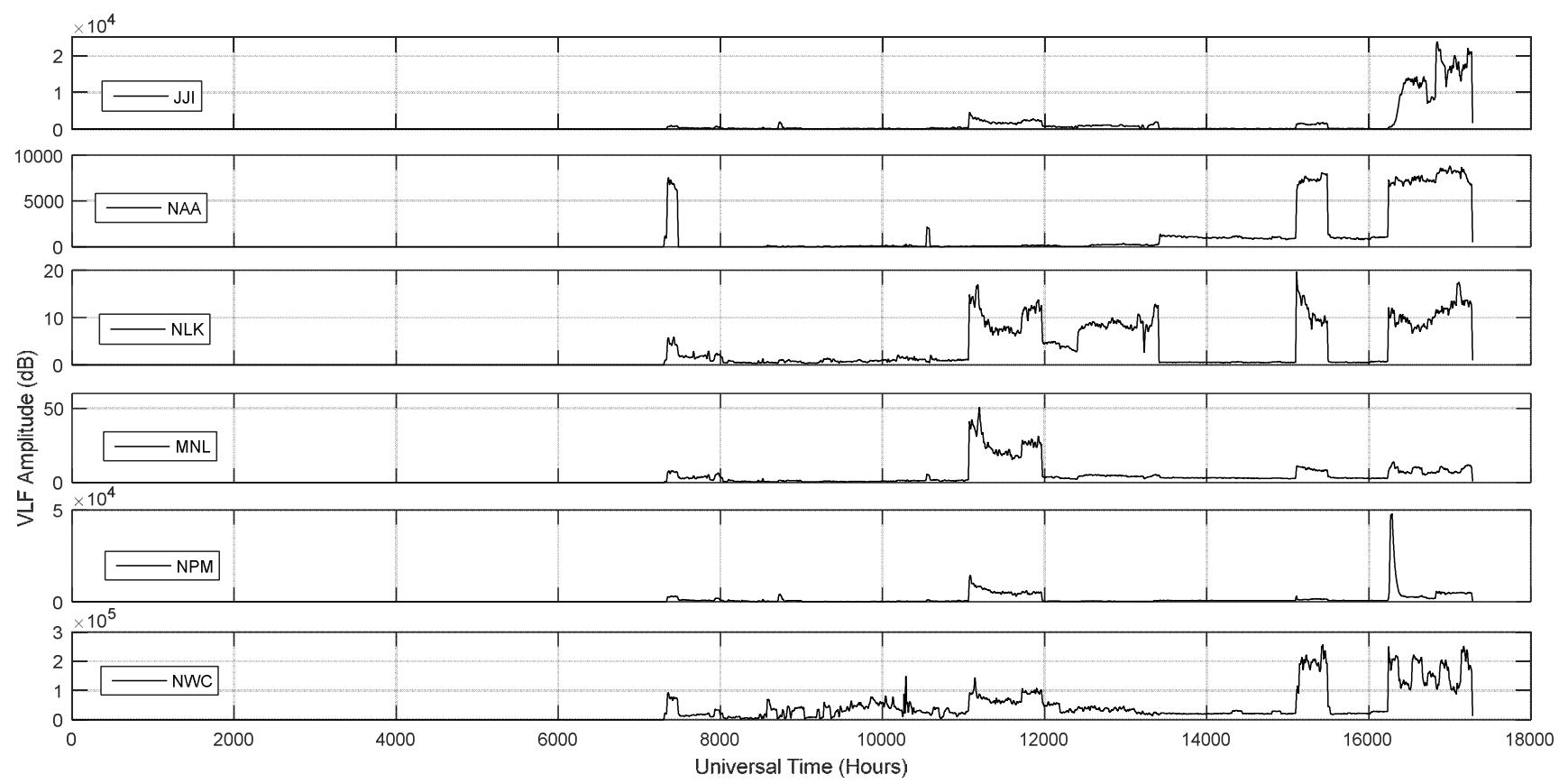

Figure 6. Diurnal variation of VLF signal from various stations received atAliero on $20^{\text {th }}$ February, 2020.

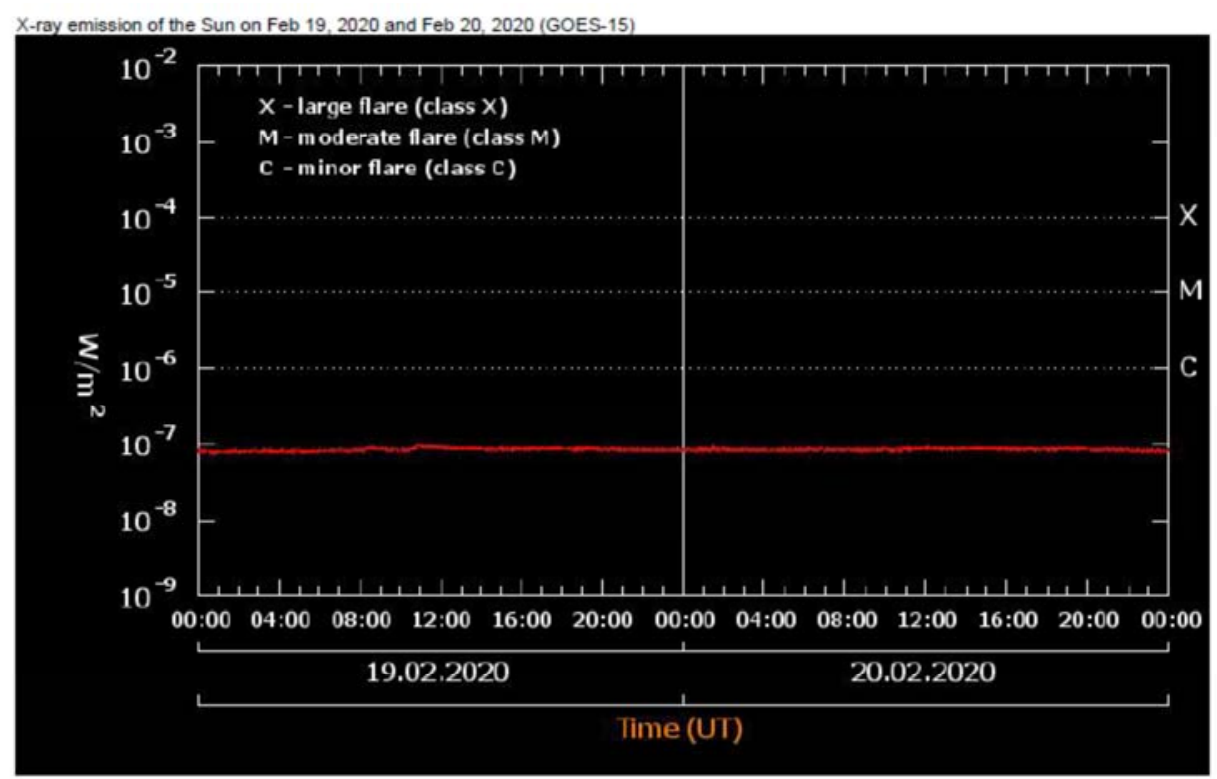

Figure 7. Solar Flares tracking for 19-20 February, 2020, obtained from the Laboratory of x-ray Astronomy of the Sun, LPI (https://tesis.lebedev.ru/en/sun flares.html? $m=2 \& d=20 \& y=2020$ ).

Figure 7 , is a plot of the solar flare observations for 19-20 February, 2020, downloaded from the website of the Laboratory of X-Ray Astronomy of the Sun. Observations from this Figure reveals that, although there was a weak geomagnetic storm on 19 February, 2020 that had an effect on the VLF signals received from various stations, yet, there 
were no traces of solar flares observed either on the 19 nor 20 February, 2020. This shows that it is possible to have weak geomagnetic storms without necessary an occurrence of solar flares. It can also be argued that not all increases in the geomagnetic activity occur as a result of the occurrence of solar flares, other factors could be responsible. Many studies $[17,3,18]$ has shown that solar flares are known to produce fast CMEs that can lead to the occurrence of different classes of geomagnetic storms. However, in the current case the observed weak geomagnetic storm, though with an impact on the VLF signals, yet, it had no any connection with solar flares.

\section{Summary and Conclusion}

The diurnal variation of the VLF signals transmitted from six stations received at the Kebbi State University of Science and Technology, Aliero, Nigeria, using the super SID monitor, has been studied during both quiet and weak geomagnetic storms. Some of the findings of the study are summarized below;

1) Signal strengths received were observed to be higher during the geomagnetically quiet conditions than the disturbed days across all the transmitting stations.

2) The signals appear to be mostly conspicuous at the ascending phase of the Dst index.

3) Signals ware observed to be stronger when the lowest values of the dst were recorded

4) Although a weak geomagnetic storm was observed on 19 February, yet, there were no traces of solar flares on that day.

5) A likelihood of the increase in the geomagnetic activity suppressing the intensity or strength of the VLF signals received was observed.

6) An increase in the solar wind speed corresponds well with the decreases in the solar wind density both on quiet and also during weak geomagnetic storm events.

It is therefore imperative to conclude from the findings of this study that; some geomagnetic storms especially the weak ones occur without any connection to the occurrence of solar flares.

In the next study, a larger volume of data will be used to track solar flares and also study their connections to different classes of geomagnetic storms.

\section{Acknowledgements}

The Authors wish to acknowledge the Stanford solar Center for the donation of the Super SID monitor used in this study. The authors also wish to appreciate the Tertiary Education Trust Fund (Tetfund) Nigeria, for the research grant provided to carry out this project. We also wish to appreciate the following Research centres/Laboratories, for making some of the data used for this research available; (i.) The German Research Center for Geosciences (http://www.gfz-potsdam.de/en/section/earths-magneticfield/data-products-services/kp-index/explanation/qd-days/) (ii.) National Space Science Data center (NSSDC) (https://omniweb.gsfc.nasa.gov/form/dx1.html), and (iii.) The Laboratory of X-ray Astronomy of the Sun, LPIRAS, Russia database (http://tesis.lebedev.ru/en/sun_flares.html).

\section{References}

[1] Pekünlü, R. (1999). Solar Flares. Turkish Journal of Physics, 23 (2), 415-423. https://doi.org/10.1017/s0252921100034461.

[2] Kumar, S., \& Singh, A. K. (2012). Effect of solar flares on ionospheric TEC at varanasi, near EIA crest, during solar minimum period. Indian Journal of Radio and Space Physics, $41(2), 141-147$.

[3] Neil R. Thomson, Craig J. Rodger, and Richard L (2004). Dowden, Ionosphere gives size of greatest solar flare, GEOPHYSICAL RESEARCHLETTERS, VOL. 31, L06803, doi: 10.1029/2003GL019345.

[4] Ezekoye, B. a, \& Obodo, R. M. (2007). The Effects of Solar Radiations on Telecommunications. The Pacific Journal of Science and Technology, 8 (1), 109-117.

[5] Abhijit C. A., B. K. De, A. Guha, and R. Roy (2015), Longduration geomagnetic storm effects on the $\mathrm{D}$ region of the ionosphere: Some case studies using VLF signal, J. Geophys. Res. Space Physics, 120, 778-787, doi: 10.1002/2014JA020738.

[6] Ugonabo, O. J., Okeke, F. N., \& Ugwu, E. B. I. (2013). Preliminary Study of Solar Flare Effects on Geomagnetic H Component at Mid Latitudes. 3 (7), 235-237.

[7] Reeves W. D., 2010; Geomagnetism tutorial, Reeve observatory anchorage, Alaska USA. 61630N: 262.89E Issue 1. 0. Last accessed, September, 2021, from: http://www.reeve.com/Documents/SAM/GeomagnetismTutori al.pdf.

[8] Gonzalez, W. D., J. A. Joselyn, Y. Kamide, H. W. Kroehl, G. Rostoker, B. T. Tsurutani, and V. M. Vasyliunas (1994), What is a Geomagnetic Storm?, J. Geophys. Res., 99 (A4), 57715792 .

[9] Tsurutani, B. T., and W. D. Gonzalez, 1997; The interplanetary cause of magnetic storms: A review in magnetic storms, Geophys., Monogr. Ser., vol. 98, Pp. 77, edited by B. T. Tsurutani, W. D. Gonzalez, Y. kamide, and J. K. Arballo. AGU, Washington DC.

[10] Kamide, Y. (1992) Is Substorm Occurrence a Necessary Condition for a Magnetic Storm? journal of geomagnetism and geoelectricity, 44, 109-117, Doi: https://doi.org/10.5636/jgg.44.109.

[11] Shweta, M., Shivalika, S., Purohit, P. K., Gwal, A. K., 2010; Effect of geomagnetic storms in the equatorial anomaly region observed from ground based data international. Journal of Geomat. Geosci. 1 (3).

[12] Joshua, B. W., Adeniyi, J. O, Amory Mazaudier, C., \& Adebiyi, 5. J. (2021) On the pre-magnetic storm signatures in NmF2 in some equatorial, low and mid-latitude stations, Journal of Geophysical Research: Space Physics, 126, c2021JA029459, https://dol.org/10.1029/2021JA029459. 
[13] Kamide, Y., Baumjohann W., Daglis I. A., Gonzalez W. D., Grande M., Joselyn J. A., McPherron R. L., Philips J. L., Reeves E. G. D., Rostoker G., Sharma A. S., Singer H. J., Tsurutani B. T., and Vasyliunas V. M., (1998) current understanding of magnetic storms: Storm-substorm relationships. Journal of Geophysical Research. Vol. 103, No. A8, Pp. 17,705-17,728.

[14] Sarkar, S. K., and B. K. De (1985), Meteorological effect on long distant $40 \mathrm{kHz}$ signal, Arch. Meteorol. Geophys. Biocl., $33 \mathrm{~A}, 365-379$.

[15] Adeniyi J. O (1986) Magnetic storm effects on the morphology of the equatorial F2 - layer. Journal of atmospheric and terrestrial physics, 48, (8): 695-702.
[16] Buonsanto, M. J., 1999; Ionospheric storms - a review. Space Sci. Rev. 88, 563-601.

[17] Knipp, D. J., Fraser, B. J., Shea, M. A., and Smart, D. F. (2018). On the little-known consequences of the 4 August 1972 ultra-fast coronal mass ejecta: Facts, commentary, and call to action. Space Weather, 16, 1635-1643. https://doi.org/10.1029/2018SW002024.

[18] Webber, W. R., McDonald, F. B., Lockwood, J. A. and B. Heikkila (2002) The effect of the July 14, 2000 "Bastille Day" solar flare event on> $70 \mathrm{MeV}$ galactic cosmic rays observed at $\mathrm{V} 1$ and V2 in the distant heliosphere, GEOPHYSICAL RESEARCH LETTERS, VOL. 29, NO. 10, 1377.10.1029/2002GL014729. 